\title{
Real-time stability evaluation of landslide based on the comparison of sliding surface and shear plane in triaxial test
}

\author{
Shunkai Liu ${ }^{\mathrm{a}}$, Wei Hu${ }^{*} \mathrm{~b}$ \\ School of Civil Engineering and Architecture, Hainan University, Renmin Road \\ 58\#,Haikou,Hainan,P.R.China 570228 \\ a665278280@qq.com, ${ }^{b}$ yilukuangben1982@163.com
}

\begin{abstract}
Keywords: landslide; monitoring data; sliding surface; shear plane; real-time stability; numerical analysis.

Abstract. The deformation characteristics of soil element depend on it's stress state, so theoretically, if the soil sampling from sliding surface of landslide was triaxial tested under the same stress state, the mechanic deformation behavior of shearing plane in test sample would have correspondence with that of sliding surface. Based on the information of landslide sliding surface confirmed by site monitoring system, the corresponding relationship of mechanic deformation behavior was searched between landslide sliding surface and shearing plane of laboratory triaxial test. The sliding stability factor of landslide was defined to be the ratio of the peak shear resistance to the real-time shear force played of soil on sliding surface, through which the real-time stability evaluation method of landslide was established based on the monitoring data. The method set up the relationship between the monitoring data on site and internal stability mechanism of landslide, which overcame the deficiency of landslide stability prediction and evaluation usually from the perspective of mathematical statistics, and also avoided the consideration of many uncertain complex factors. The method was used to evaluate the stability of a numerical slope model and compared with three other traditional methods. Although the evaluation result was slightly higher than the traditional methods, it's within a reasonable range, and the new method can be used to do the real-time evaluation which overcame the shortage of traditional method only for static.
\end{abstract}

\section{Introduction}

Slope stability research shows that, both of qualitative and quantitative analysis cannot reasonably use monitoring data to explore the stability mechanism of landslide in depth(Y.R. Zheng, et al. 2004; R. Rui, et al. 2013; G.Q. Chen, et al. 2004), and the Reliability also cannot rule out the influence of many external uncertainties(D.Wang, et al. 2012). The soil sampling from sliding surface of landslide was triaxial tested under the same stress state, which was determined by the field monitoring information of landslide sliding surface, and the stress-stain curve of shear plane was obtained. The corresponding relationship of mechanic deformation behavior was searched between landslide sliding surface and shearing plane of laboratory triaxial test, i.e., the real-time stress on the sliding surface was the one on the stress-stain curve of shear plane with the same shear strain, which was determined by the field monitoring data. The real-time stability coefficient of landslide was defined by the ratio of peaked shear stress on the stress-stain curve to the real-time value. The validity of the method was verified by the comparison with traditional methods at last.

\section{Deformation analysis of sliding surface}

The location of sliding surface of landslide can be ascertained by the layout of deep inclinometers. The sliding surface angle $\theta$ between two adjacent inclinometer boreholes can be calculated by the ratio of sliding surface depth differences in two adjacent boreholes to the horizontal distance between them. If the horizontal distance $\mathrm{L}$ is small enough, the sliding surface can be simplify expressed by a straight line (Fig.1). The horizontal displacement $L_{1}$ of the slip body is calculated by the monitoring data of inclinometers in the hole; then the relative displacement of the sliding surface can be calculated by $\theta$ and $L_{l}$ (Fig.2). The average slip strain is defined as the ratio of slide out area $S_{l}$ and 
sliding surface area $S_{2}$. The equation is written as

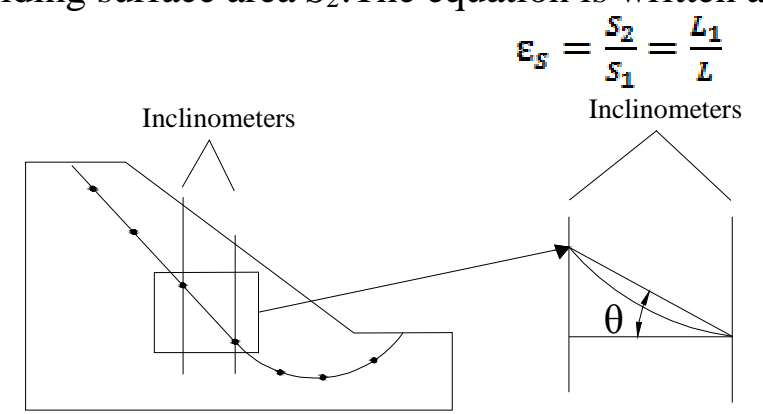

Fig.1 Layout of inclinometers and simplified of sliding surface

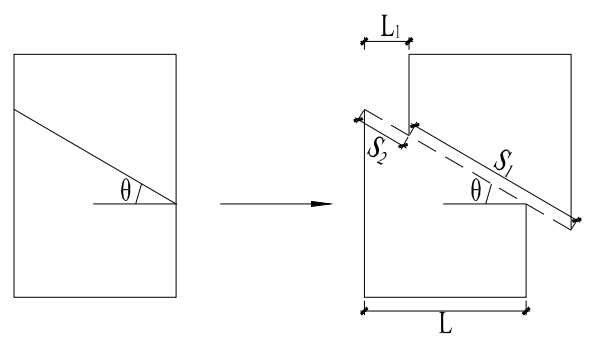

Fig.2 Displacement of sliding surface

\section{Stress state analysis of soil element}

Fig. 3 shows the plane strain stress state of soil element on the sliding surface and the analysis of principal stress. The angle $\theta$ of the sliding surface to the horizontal plane is the rupture angle of soil mass. Vertical self-weight stress is calculated as $\sigma_{z}=\gamma \mathrm{ch}$; horizontal self-weight stress is calculated as $\sigma_{\mathrm{X}}=\mathrm{K}_{0} \sigma_{\mathrm{Z}}\left(\mathrm{K}_{0}\right.$ is the static lateral pressure coefficient $) ; \varphi$ is the friction angle of soil.

The relationship of angles in Fig.3 is as follows: $\alpha_{0}$ is the angle of the main stress $\sigma_{1}$ to the horizontal direction. $\theta-\left(90^{\circ}-\alpha_{0}\right)$ is the angle of the soil fracture surface to the direction of $\sigma_{3}$. According to Mohr-Coulomb strength theory, the angle between the soil fracture surface and $\sigma_{3}$ can also be expressed as $45^{\circ}+\varphi / 2$, then there has

$\theta-\left(90^{\circ}-\alpha_{0}\right)=45^{\circ}+\varphi / 2$.

$\alpha_{0}$ can be expressed as

$$
\alpha_{0}=3 \pi / 4-\theta+\varphi / 2 \text {. }
$$

The shear stress on the fracture surface of soil element can be calculated as

$$
\tau_{x z}=\frac{\tan \left(-2 \alpha_{0}\right)\left(\sigma_{Z}-\sigma_{X}\right)}{2} \text {. }
$$

Substituting $\alpha_{0}$ into the equation [2], which can get the equation of main stress

$$
\begin{aligned}
& \sigma_{1}=\frac{1}{2}\left(\sigma_{\mathrm{Z}}-\sigma_{\mathrm{X}}\right)+\frac{1}{2} \sqrt{\left[1+\cot ^{2}(2 \theta-\varphi)\right]\left(\sigma_{\mathrm{Z}}-\sigma_{\mathrm{X}}\right)^{2}}, \\
& \sigma_{3}=\frac{1}{2}\left(\sigma_{\mathrm{z}}-\sigma_{\mathrm{X}}\right)-\frac{1}{2} \sqrt{\left[1+\cot ^{2}(2 \theta-\varphi)\right]\left(\sigma_{\mathrm{Z}}-\sigma_{\mathrm{X}}\right)^{2}} .
\end{aligned}
$$

$\sigma_{3}$ is the confining pressure of soil element on sliding surface, which provides stress setting basis for triaxial test.

\section{Deformation analysis of Shear plane in triaxial test sample}

According to the normally drainage boundary conditions of landslide, consolidated-undrained type is chose for triaxial test. In triaxial test, the sample is sliding along the shear plane and radial bulging at the same time (Fig.4).

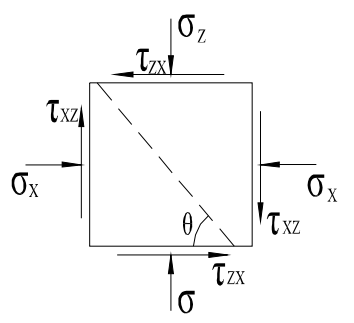

Fig.3 Stress state of soil on sliding surface

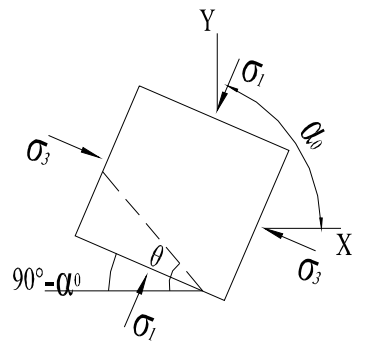

It is difficult to calculate the area of shear plane account. Therefore, it is necessary to distinguish the influence of them, and calculate corresponding shear strain on shear plane respectively. The axial strain and radial strain corresponding to two kinds 
of deformation can be written as

$$
\begin{aligned}
& \varepsilon_{1}=\varepsilon_{1}^{\prime}+\varepsilon_{1}^{\prime \prime}, \\
& \varepsilon_{3}=\varepsilon_{3}^{\prime}+\varepsilon_{3}^{\prime \prime},
\end{aligned}
$$

where $\varepsilon_{1}{ }^{\prime}$ is the axial strain caused by shearing deformation, and $\varepsilon_{3}{ }^{\prime}$ is the relevant radial strain; $\varepsilon_{1}{ }^{\prime \prime}$ is the axial strain caused by radial bulging, and $\varepsilon_{3}{ }^{\prime \prime}$ is the relevant radial strain.

In consolidated-undrained triaxial test, $\varepsilon_{3}$ of the minimum radial deformation direction can be deemed as completely caused by bulging, and $\varepsilon_{v}=0$. So there has $\varepsilon_{3}=\varepsilon_{3}{ }^{\prime \prime}$ and $\varepsilon_{1}{ }^{\prime \prime} / 2=-\varepsilon_{3}{ }^{\prime \prime}$, and then, $\varepsilon_{1}{ }^{\prime}$ can be calculated.

The axial strains under these two kinds of deformation are calculated as follows:

1) If the slip surface is very obvious, the slide out area $A_{l}$ is calculated by Eq.9.

$$
A_{1}=\frac{\pi R^{2}}{4 \cos \psi}-4 \int_{\frac{2 \cos \psi}{2 \sin \psi}}^{\frac{R}{1-\left(\frac{2 X \cos \psi}{R}\right)^{2}}}=\frac{R^{2}(\pi-2 \beta-\sin 2 \beta)}{4 \cos \psi},
$$

where $\Delta h=\varepsilon_{1}{ }^{\prime} h ; R$ is the diameter of sample, and $\mathrm{h}$ is the height; $\Psi^{\prime}$ is the angle of shear plane to the horizontal plane.

The shear strain of shear plane is defined as the ratio of slide out area $A_{l}$ to the sliding surface area $A$, there has

$$
\varepsilon_{S Z}^{\prime}=\frac{A_{1}}{A}=\frac{\pi-2 \beta+\sin (2 \beta)}{\pi} .
$$

2) When the bulging deformation is obvious, the shear strain is defined as the ratio of bulging area $A_{2}$ to $A$, i.e.

$$
\varepsilon_{S z}^{\prime \prime}=\frac{A_{2}}{A}=\frac{\frac{\pi R^{2}}{4 \cos \psi}\left(1+\frac{\varepsilon_{1}^{\prime \prime}}{2}\right)^{2}-\frac{\pi R^{2}}{4 \cos \psi}}{\frac{\pi R^{2}}{4 \cos \psi}}=\left(1+\frac{\varepsilon_{1}^{\prime \prime}}{2}\right)^{2}-1 .
$$

The total shear strain of shear plane can be obtained as

$$
\varepsilon_{s z}=\varepsilon_{s z}^{\prime}+\varepsilon_{s z}^{\prime \prime}=\frac{\pi-2 \beta+\sin (2 \beta)}{\pi}+\left(1+\frac{\varepsilon_{1}^{\prime \prime}}{2}\right)^{2} \text {. }
$$

Eq.12 shows the corresponding relationship between shear strain $\varepsilon_{s z}$ and the axial strain $\varepsilon_{1}$, so the shear stress-shear $\operatorname{strain}\left(\tau-\varepsilon_{\mathrm{sz}}\right)$ curve of shear plane can be obtained by the converted of stress-strain $\left(\left(\sigma_{1}-\sigma_{3}\right)-\varepsilon_{1}\right)$ curve of triaxial test.

\section{Evaluation of real-time stability}

The average relative slip strain $\varepsilon_{s}$ of each section sliding surface is determined by EQ.1. $\tau$ - $\varepsilon_{s z}$ curve is extracted by triaxial test on the soil element of corresponding sliding surface with under same condition. According to the reciprocity principle of sliding surface and shear plane, The shear stress $\tau_{\mathrm{s}}$ corresponding to $\varepsilon_{s}$ will be found out in $\tau$ - $\varepsilon_{s z}$ curve because of $\varepsilon_{s z}=\varepsilon_{s} . \tau_{\mathrm{s}}$ is the real-time shear stress exerted by soil element on the sliding surface. The peak shear stress $\tau_{u l t}$, when the soil element is destroyed, can also be obtained from $\tau-\varepsilon_{\mathrm{sz}}$ curve. Or it can be calculated by the strength parameters. The stability coefficient of this sliding section can be defined as the ratio of $\tau_{\mathrm{ult}}$ to $\tau_{s}$, there has

$$
F_{s}=\frac{\tau_{u l t}}{\tau_{s}}
$$

To the total sliding surface, The stability coefficient can be gave as

$$
F_{s}=\frac{\tau_{u l t 1} \times A_{1}+\tau_{u l t 2} \times A_{2}+\cdots+\tau_{u l t n} \times A_{n}}{\tau_{s 1} \times A_{1}+\tau_{s 2} \times A_{2}+\cdots+\tau_{s n} \times A_{n}} .
$$

Where $\mathrm{A}_{\mathrm{i}}$ is the area of $\mathrm{i}$ th block; and $\tau_{\mathrm{ulti}}, \tau_{\mathrm{si}}$ are the corresponding peak shear stress and real-time shear stress exerted of soil element respectively.

\section{Numerical simulation of slope}

The geometries of numerical slope body is $20 \mathrm{~m}$ high and $20 \mathrm{~m}$ long, with the slope of $1: 1$, and slope surface is linear, as shown in fig.5. The boundaries are fixed on bottom and two sides, while the top is 
free.

Duncan-Chang model is used for the soil, and relevant parameters are shown in Table 1 based on triaxial test. Besides that, elasticity modulus $E=20 \mathrm{MPa}$, poisson ratio $v=0.495$.

Table 1 Soil parameters

\begin{tabular}{|c|c|c|c|c|c|c|c|c|}
\hline $\mathrm{S}_{\mathrm{r}}$ & $\mathrm{c}[\mathrm{kPa}]$ & $\varphi\left[^{\circ}\right]$ & $\mathrm{K}$ & $\mathrm{N}$ & $\mathrm{R}_{\mathrm{f}}$ & $\mathrm{G}$ & $\mathrm{K}_{\mathrm{ur}}$ & $\rho\left[\mathrm{kg} \cdot \mathrm{m}^{-3}\right]$ \\
\hline $30 \%$ & 14.579 & 23.294 & 6.770 & 0.643 & 0.840 & 0.49 & 16.693 & 1500 \\
\hline $40 \%$ & 10.773 & 22.469 & 0.576 & 0.487 & 0.750 & 0.49 & 1.440 & 1550 \\
\hline $50 \%$ & 6.887 & 21.644 & 0.286 & 0.355 & 0.713 & 0.49 & 0.715 & 1600 \\
\hline
\end{tabular}

\section{Real-time stability evaluation method}

Displacement nephogram of slope shows that, the sliding surface is roughly a circular arc under different degrees of saturation. In the course of real-time stability evaluation, the displacement of monitoring points should be exacted. Firstly, the circular arc slide surface is divided into 6 sections firstly and the displacements of 7 relevant points are extracted as shown in Fig.6. Three parts of stability factor are calculated using displacement data of each item block based on real-time stability factor. As shown in Table 2, shearing strain, real-time exerted shearing stress and ultimate shearing stress of the soil element in sliding surface of each body, and real-time stability factors are calculated under different degrees of saturation.

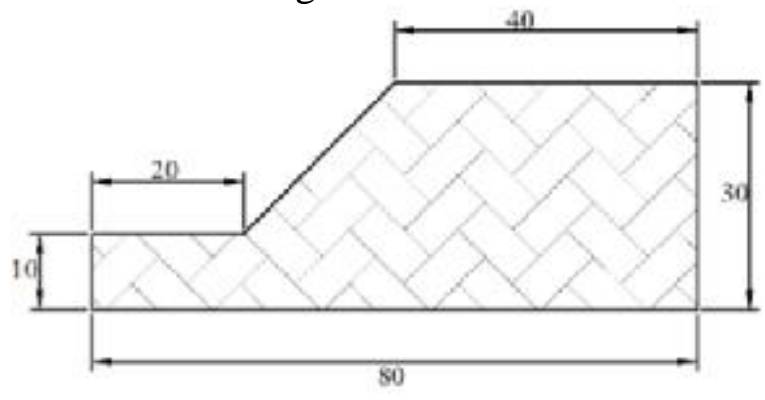

Fig.5 Model dimensions (unit: $\mathrm{m}$ )

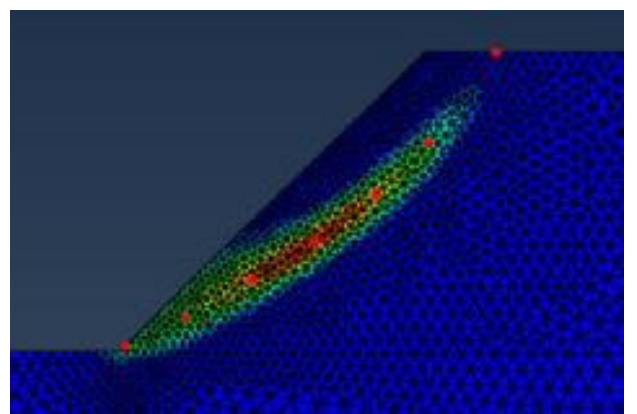

Fig.6 Layout of monitoring points

Table 2 Real-time stability factor of single slice

(Where R means real-time, and U means ultimate. The unit of stress is $\mathrm{kPa}$.)

\begin{tabular}{|c|c|c|c|c|c|c|c|c|c|}
\hline B. 1 & $\begin{array}{l}\text { Shear } \\
\text { strain }\end{array}$ & $\begin{array}{c}\text { R-shear } \\
\text { stress }\end{array}$ & $\begin{array}{l}\text { U-shear } \\
\text { stress }\end{array}$ & $\overline{F_{s}}$ & B. 4 & $\begin{array}{l}\text { Shear } \\
\text { strain }\end{array}$ & $\begin{array}{c}\text { R-shear } \\
\text { stress }\end{array}$ & $\begin{array}{l}\text { U-shear } \\
\text { stress }\end{array}$ & $\overline{F_{s}}$ \\
\hline $30 \%$ & 1.738 & 48.673 & 54.271 & 1.115 & $30 \%$ & 2.162 & 81.342 & 91.917 & 1.130 \\
\hline $40 \%$ & 1.959 & 26.705 & 26.705 & 1.007 & $40 \%$ & 2.456 & 51.658 & 51.658 & 1.000 \\
\hline $50 \%$ & 2.659 & 14.068 & 14.068 & 1.000 & $50 \%$ & 3.582 & 45.353 & 45.353 & 1.000 \\
\hline B. 2 & $\begin{array}{l}\text { Shear } \\
\text { strain }\end{array}$ & $\begin{array}{c}\text { R-shear } \\
\text { stress }\end{array}$ & $\begin{array}{l}\text { U-shear } \\
\text { stress }\end{array}$ & $\overline{F_{s}}$ & $\overline{\mathrm{B} .5}$ & $\begin{array}{l}\text { Shear } \\
\text { strain }\end{array}$ & $\begin{array}{c}\text { R-shear } \\
\text { stress }\end{array}$ & $\begin{array}{l}\text { U-shear } \\
\text { stress }\end{array}$ & $\overline{F_{s}}$ \\
\hline $30 \%$ & 1.796 & 80.841 & 91.917 & 1.137 & $30 \%$ & 2.143 & 82.215 & 91.917 & 1.118 \\
\hline $40 \%$ & 2.041 & 51.146 & 51.658 & 1.010 & $40 \%$ & 2.435 & 50.944 & 51.658 & 1.014 \\
\hline $50 \%$ & 2.823 & 445.353 & 45.353 & 1.000 & $50 \%$ & 3.313 & 45.353 & 45.353 & 1.000 \\
\hline B.3 & $\begin{array}{l}\text { Shear } \\
\text { strain }\end{array}$ & $\begin{array}{c}\text { R-shear } \\
\text { stress }\end{array}$ & $\begin{array}{l}\text { U-shear } \\
\text { stress }\end{array}$ & $\overline{F_{s}}$ & B.6 & $\begin{array}{l}\text { Shear } \\
\text { strain }\end{array}$ & $\begin{array}{c}\text { R-shear } \\
\text { stress }\end{array}$ & $\begin{array}{l}\text { U-shear } \\
\text { stress }\end{array}$ & $\overline{F_{s}}$ \\
\hline $30 \%$ & 2.445 & 114.500 & 130.072 & 1.136 & $30 \%$ & 1.687 & 49.973 & 54.271 & 1.086 \\
\hline $40 \%$ & 2.774 & 98.880 & 98.880 & 1.000 & $40 \%$ & 1.921 & 26.493 & 26.705 & 1.008 \\
\hline $50 \%$ & 3.367 & 89.203 & 89.203 & 1.000 & $50 \%$ & 2.350 & 13.962 & 14.068 & 1.000 \\
\hline
\end{tabular}

Take the single item results above into Eq.14, the total stability factor of slope can be obtained as shown in Table3. 
Table 3 Real-time stability factor of slope

\begin{tabular}{cccc}
\hline $\mathrm{S}_{\mathrm{r}}$ & $30 \%$ & $40 \%$ & $50 \%$ \\
\hline $\mathrm{F}_{\mathrm{s}}$ & 1.120 & 1.006 & 1.000 \\
\hline
\end{tabular}

\section{Contrastive analysis}

The slope stability factor is also calculated by three other methods including transfer coefficient method, Bishop slices method and Sweden slices method, the sliding surface and the slices division method are the same to the real-time stability factor method. The results are shown in Table 4 . Compare to two slices methods, the result of real-time stability evaluation method is generally higher than that of limit equilibrium analysis. For $\mathrm{Sr}=30 \%$, slope is stable according to the result; for $\mathrm{Sr}=40 \%$ or $\mathrm{Sr}=50 \%$, slope has been slid and the stability factors are very close to each other. Although there is a little gap between two specific data, the results are consistent, which shows reasonable of the method in some degree.

Table 4 Safety factor of limit equilibrium method

\begin{tabular}{cccc}
\hline $\mathrm{S}_{\mathrm{r}}$ & Transfer coefficient & Bishop slices & Sweden slices \\
\hline $30 \%$ & 1.029 & 1.025 & 0.965 \\
$40 \%$ & 0.896 & 0.892 & 0.893 \\
$50 \%$ & 0.757 & 0.767 & 0.707 \\
\hline
\end{tabular}

\section{Conclusion}

This method carry out stability evaluation of slope based on the real-time monitoring data of displacement, the mechanical concept is clear and many uncertain complex natural factors can be avoided. Directly relationship has been established between monitoring data and landslides intrinsic stability mechanisms, which provide practical and convenient way for the real-time stability evaluation of landslide. Contrast with three other traditional landslides stability evaluation methods, the results show that the stability factor of real-time method is a little higher than that of traditional methods, but the judgment is consistent, and the key is the method of this work has the real-time property.

\section{Acknowledgements}

This work was financially supported by National Natural Science Foundation of China(51508141), Hainan Association for S\&T innovation Program of Youth Talents(201506).

\section{References}

[1] Y.R.Zheng, S.Y. Zhao: submitted to Chinese Journal of Rock Mechanics and Engineering (2004).(In Chinese)

[2] R.Rui, X.L.Hu, H.M.Tang, C.D.Li, J.W.Ma and W.Y.Song: submitted to Journal of Rock and Soil Mechanics (2013). (In Chinese)

[3] G.Q.Chen, R.Q.Huang, Y.C.Shi and Q.Xu: submitted to Chinese Journal of Rock Mechanics and Engineering(2004). (In Chinese)

[4] D.Wang, L.Z.Cao, C.D,Pu, Y.D.Xue and R.C.Bai: submitted to Chinese Journal of Rock Mechanics and Engineering(2012). (In Chinese) 